\title{
Podcasts as a method of teaching the system of precedent texts in the language of sustainable education
}

\author{
Alla Evtyugina*, and Lydia Volkova \\ Russian State Vocational Pedagogical University, st. Mashinostroiteley, 11, 620012 Yekaterinburg, \\ Russia
}

\begin{abstract}
The relevance of the problem under study is due to the increasing number of foreign students studying Russian and the need to expand approaches to their education in this area, taking into account the current state of the Russian language, its contextuality and precedence. The article is aimed at identifying the need to distinguish precedent units as a separate discipline for the course "Russian as a foreign language" and the selection of methodological tools that are relevant for this discipline, allowing students to develop speech skills based on the current state of Russian speech. The leading approach to the study of this problem is the method of predictive modeling, which makes it possible to identify the likely advantages of introducing methodological innovations into educational practice. Also, the research methods were a survey with subsequent analysis of the data obtained. The article substantiates the expediency of identifying a separate discipline based on precedent texts for students of Russian as a foreign language, based on the methodological use of educational podcasts. The materials of the article are of practical value for teachers of Russian as a foreign language in higher educational institutions.
\end{abstract}

\section{Introduction}

Modern methods of teaching a foreign language today are aimed not only at the formation of language competence in the field of speaking, listening, reading, writing, but above all at the linguocultural aspect of language learning, which involves the assimilation of values, customs, traditions of a foreign culture. The linguocultural approach is currently very relevant to the methodology of teaching Russian as a foreign language (RFL) and, being meta-competence, contributes to the painless and more successful integration of foreign language students into the Russian-speaking society [2]. Due to the fact that the teaching of successful communication is based on the ability not only to convey information to the recipient in an acceptable form, but also to make it possible to understand words and expressions with national and cultural semantics, cultural and speech facts that are not clear to a non-native speaker of the Russian language. These are the precedent texts that allow the linguistic person to participate more successfully in the communicative act.

Coresponding author: alena.seven@mail.ru 
The study of precedent texts in the field of Russian as a foreign language is presented in the works of V.A. Burvikova, N.S. Valgina, V.G.Kostomarova, D.O. Dobrovolsky, O.V. Lisochenko, N.D.Lukina, N.V.Petrova. The concept of precedent text was introduced into scientific circulation by the famous Russian linguist Y.N. Karaulov, who distinguished three most important features for determining precedent signs: "significant for a particular person in cognitive and emotional terms;having a supra-personal character, that is, wellknown to the wider environment of a given personality, including her predecessors and contemporaries; texts, the reference to which is renewed repeatedly in the discourse of a given linguistic reality; phenomena (linguistic and extralinguistic), well-known to members of a particular society (from family to national-cultural community), included in the complex cognitive space of communicants "[12].

There is the definition used in the article, which is proposed by one of the authors, when the precedent texts are considered as "cultural and aesthetic signs that act as the basic units of the motivational level of a linguistic personality" [5]. It should be emphasized that "the use of these units in speech characterizes not only the level of erudition and cultural knowledge of the author of the statement, but also reveals a range of values, attitudes, an aesthetic attitude to reality, the nature of speech intention" [5].This is the approach, demonstrating the inclusion of these signs in the national culture, that gives a clear understanding of the need to study them in the context of foreign language education. In a speaker's speech, precedent units not only show the level of language proficiency, but also serve as a kind of marker in the context of "native - foreign", which is important in Russianspeaking discourse.

Examplesofusecasesinclude: well-knownquotes «надо, Федя, надо; счастливые часов не наблюдают; а судьи кто?; жди меня, и я вернусь; трус не играет в хоккей; молилась ли ты на ночь, Дездемона?; врагу не сдается наш гордый Варяг; как здорово, что все мы здесь сегодня собрались; что тебе снится, крейсер Аврора?; позови меня тихо по имени; отчего так в России березы шумят?; во всех ты, душенька, нарядах хороша; отчего люди не летают как птицы?; у природы нет плохой погоды». Names of works of literature and art: «луч света в темном царстве; праздник, который всегда с тобой; кавказская пленница; поле чудес; недоросль; горе от ума; Москва слезам не верит; дети подземелья; Маугли; человек-невидимка; преступление и наказание; три богатыря». Proper names: «Онегин; Екатерина Великая; Наполеон; Офелия; Конек-горбунок; Василиса прекрасная; Гамлет; Левитан; Эйнштейн; Шумахер; Пушкин; Иван Сусанин; Иуда».

The emphasizing of precedent texts as a separate stage of teaching RFL has long remained a discursive issue.Methodists (A.V. Tekuchev, L.A. Piotrovskaya, M.A. Chernyak, V.A. Efremov, etc.)disagree on whether special attention should be paid to such an ambiguous linguistic phenomenon, if the purpose of the main studyof language as a foreign language in the overwhelming majority of cases is studying or working in Russia, which does not involve appealing to such phenomena and understanding their place in the usus of the Russian language.However, the well-known methodologist-philologist A.N.Schukin proved the direct dependence of communicative failures of a sociocultural nature on the lack of command of precedent texts. The researcher notes that the obvious supra-personal nature of precedent phenomena not only makes them incomprehensible to a foreign citizen, but also significantly complicates independent understanding or "guessing" the correct meaning. This happens because the case text is a complex linguistic sign, whose set of expressions is not equal to its content.

In our opinion, this will not only provoke a "communicative conflict" that arose on the basis of misunderstandings, but also obviously put a foreign student in an awkward position and create a stressful situation "that has the opportunity to negatively affect further motivation to study Russian as a foreign language" [6]. In the conditions of study in higher 
educational institutions, the teacher of RFL should pay attention to possible communication errors and even communicative "suicides" in order to prevent them before they appear and take root in the students' speech. The precedent texts are the most difficult for foreign students to understand, therefore it is necessary to allocate a separate place for them in the speech practice of students. Despite this obvious thought, this does not happen for a number of disappointing reasons.

- In the conditions of optimization of university education, teachers are focused on the transfer of theoretical knowledges, in this regard, there is little time left for the practical development of the material. The study of the precedence of a sign only in a theoretical aspect will not give the desired result, since there is no universal algorithm for determining the sources of extralinguistic features and the reasons for using precedent phenomena in the context of Russian-language discourse;

- Many methods of teaching RFL are aimed at memorizing new lexical units and their subsequent implementation in practical tasks that develop basic language competencies. For precedent texts, such an approach is not appropriate, since their system of using differs significantly from frequency units and requires separate consideration. We believe that the presentation of precedent texts along with the main lexical layer of the Russian language system will cause confusion and incomplete understanding of the studying linguistic units;

- The choice of precedent texts for inclusion in the process of teaching RFL is a complex process, therefore, teachers often limit themselves to only the most famous (often phraseological or folklore) units in the context of the time constraints of the RFL program.

All of the above tells us not only about the existence of the problem of unstructured teaching to understand and use precedent texts in the RFL methodology, but also about the need to highlight the study of precedent texts as a separate discipline, no less important than the grammar of the Russian language at levels B1 and C especially. The choice of precedent phenomena may depend on the level of preparedness of students and educational tasks designated by a particular institution, but the problem of expanding the scope of teaching precedent in the context of RFL definitely exists [10].

The possibility of defining precedent phenomena as a separate discipline in the conditions of teaching RFL, in our opinion, can be seen in the cultural-linguistic concept of language learning proposed by E.I.Passov. "Teaching a language in close interaction with culture allows participants in intercultural communication not only to get acquainted with facts from the field of a foreign language culture and acquire the ability to use them in various communication situations, but also to master the abilities: to see the connection between the fact of culture and the verbal expression that denotes it and eliminating stereotypes, both about the culture being studied, and about the culture that is native to the student "[9].

In addition, with a lot of support in educational circles, the trend of integrating cultural facts into language education also allows us to understand that the teacher should go from linguistic units to cultural units.This seems obvious, since when studying a foreign language, which in our case is Russian, it is the perceptions of it that form a secondary linguistic personality capable of synthesis with an initially alien society and, consequently, consciousness.

Evidence in favor of highlighting precedent texts as a separate discipline is also the complexly structured system of formation of the speech ability to understand and use the precedent unit, identified by E.S Brichevskaya, E.Y.Popova and E.G.Rostov.According to their research, a student must go through several stages in order to gain a full productive understanding of the precedent phenomenon. 
1. "Perception of the form of the precedent text". This stage is due to the fact that the precedent texts are very different in the time of occurrence and the time of their continued use.In this regard, the grammatical structure of the precedent text may be different from the modern structure of phrase construction. The student needs to understand that the precedent text often includes neologisms, archaisms, historicisms, little-used vocabulary and learns to distinguish them from ordinary phrases with these units, relying on the context in the absence of cliché in their structure.

2. "Understanding the meaning of the case text. Understanding the semantics of a precedent text is a multidimensional process: the meaning it realizes is inseparably linked with the situation where it is used and with a certain cultural knowledge, component. The task of the teacher in this case is to explain to the students the specifics of actualizing a particular precedent text, modeling certain communicative situations in which the precedent text (or several precedent texts) can be used" [8].

3. "Understanding the cultural value determined by the precedent text". When submitting material bases on precedent texts, the teacher needs to understand that he not only forms new images and semantic connections in the minds of students, but also encourages them to look for similar things in their native language systems, which is not always possible or for certain correct.With a successful solution of this educational task, the teacher will be able not only to expand the vocabulary of students, but also to help them understand the similarities and differences of cultural values, to form an understanding of the national-historical specifics, which will undoubtedly affect further communication with the native speakers of the target language [10].

4. "Active and appropriate use of the precedent text in different communicative situations". Undoubtedly, this stage is the most difficult for both students and teachers, as it directly affects the ability of students to communicate not only at the linguistic, but also at the intercultural level. The mastery of this ability characterizes not only the completeness of the formation of a secondary linguistic personality, but also full awareness of a different social reality.

Thus, we can say that the need for special attention to precedent signs in the process of teaching RFL is due to several factors: a complex system of assimilation and explanation of the peculiarities of using precedent texts, which requires more time than the basic program of RFL; referring precedent texts to the category of special reflectors of a foreign language culture and mentality, allowing not only to study them separately, but also to carry out a comparative analysis with the peculiarities of the native culture; a more complex method of preventing communication failures caused by the ambiguity and extraordinary complexity of the precedent sign; the lack of a universal method for identifying and understanding precedent texts, justified by the temporal vastness of their selection and use, as well as a large number of sources of origin.

\section{Materials and methods}

During the research, the following theoretical methods were used: analysis of linguistic, psychological and pedagogical, philological and scientific-methodical literature, materials of scientific and practical conferences, dissertations on the topic of research.The main method was empirical, namely the analysis and interpretation of the results obtained, a conversation and a diagnostic survey of students during the experiment, an evaluative study proposed to teachers, modeling practical approaches to improving the educational environment in conditions of teaching RFL based on the results obtained. 


\section{Results and discussion}

The feasibility of implementing the above idea is reflected in practical work with three groups of foreign first-year undergraduate students (from the countries of Tajikistan, Uzbekistan, Turkmenistan, Kazakhstan) of the Russian State Professional Pedagogical University in a total of 90 people, whose main specialization is economics and management and information technology.These groups study Russian language in the format of immersion in the language environment and in additionally organized university courses.All the students participating in the study had B1 language proficiency upon their arrival in Russia.After six months of studying this discipline by foreign students, despite the apparent success, we conducted a survey related to their progress in understanding and using the Russian language. The survey contained the following points:

- "What is the most difficult thing for you at this stage of learning Russian?Answers: to speak, to listen, to comprehend, to read, to write";

- "What is easiest for you at this stage of learning Russian?- Answers: to speak, to listen, to comprehend, to read, to write."

- Below are the results of the survey.

Table 1. Results of the survey

\begin{tabular}{|c|c|c|c|c|c|}
\hline $\begin{array}{c}\text { Type of } \\
\text { speech } \\
\text { activity }\end{array}$ & Speaking & Listening & Comprehension & Reading & Writing \\
\hline The easiest & $9 \%$ & $13 \%$ & $17 \%$ & $28 \%$ & $33 \%$ \\
\hline $\begin{array}{c}\text { The most } \\
\text { difficult }\end{array}$ & $34 \%$ & $22 \%$ & $17 \%$ & $21 \%$ & $18 \%$ \\
\hline
\end{tabular}

Based on our practical observation, we can conclude that it is easiest for students to learn mechanical types of speech activity, which include "reading" and "writing", as the most difficult are "listening" and "speaking". The revealed results allowed us to assume that after six months of studying Russian as a foreign language, the communicative function of the language remains the least developed among students, the direct implementation of which is required by foreign students in the course of their daily activities.

In order to identify the specific cause of the problem, we interviewed 4 teachers of the course about why specific foreign students may experience difficulties in the process of everyday communication in the Russian-speaking community. The answers we proposed were as follows: "1. A large number of precedent units in the Russian language system"; "2. A high number of modern foreign borrowings"; «3. Individual factors: rate of speech, peculiarities of articulation and intonation of individual Russian speakers"; «4. Emotional constraint when appealing by means of a foreign language system"; "five. Lack of lexical knowledge "; We asked each of the teachers to rate the significance of the individual factors presented on a scale from 1 to 5 .

The following are the results of the survey (the answer options in the diagram are expressed in numbers for the convenience of data analysis) (Fig.1): 


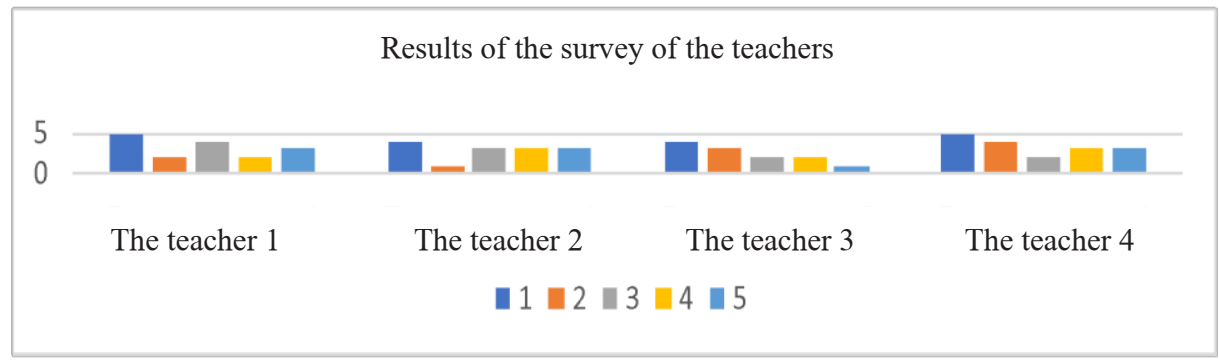

Fig. 1. Results of a survey of teachers on the topic "The reasons for the communication difficulties of foreign students in the Russian-speaking community"

Analyzing the results, we can notice that the most stable high assessment (4-5 points) of significance as an obstacle to the implementation of the communicative function was received by condition number one, namely: "a large number of precedent units in the Russian language system."Also, linking the results of the survey of teachers with the initial diagnostic survey of students, we can make the assumption that the understanding of precedence may be violated not only due to the erroneous determination of their immediate meaning, but also due to the fact that in a dense stream of speech it may be difficult for a student to identifyyourself a separate precedent unit by ear and analyze it in order to reproduce it later in your own speech utterance, focused on the created speech situation.

The greatest psychological and mechanical difficulties in students are caused by the mastery of auditory skills $[9,11]$.Auditory skills are speech skills brought to automatism and associated with recognizing and distinguishing by ear of individual sounds and sound complexes, including various types of intonation structures in the flow of speech.The development of auditory skills seems to be the leading task of this type of speech activity as listening.

Listening is the process of perceiving and understanding speech by ear, where perception is the analysis and synthesis of the material means of language, and understanding is the result of the analysis and synthesis of the semantic meanings of these means.

It should be noted that listening and auditory skills are a kind of "base" for the development of other types of speech activity in the study of Russian as a foreign language. At the same time, auditory skills can be called the most difficult to learn. For students, this is due, first of all, to the lack of the necessary element of clarity, in which it is possible to visually assess the source of audio information. Hence, a certain psychological barrier arises, a certain fear of too "abrupt" immersion in the language environment. Usually, a student at different stages of language learning is lost, even if it is not the first time, he hears audio materials. This is confirmed by the studies of A.A. Mirolyubova, in which she claims that a person perceives only $30 \%$ of all the information heard, since his acoustic perception and auditory canals are insufficiently developed. Usually, in the course of studying RFL, like other foreign languages, the emphasis is on the student's visual analyzers, which is an almost unsuccessful strategy for developing auditory skills. Visibility prevails over other channels of perception and the student becomes even psychologically and cognitively focused only on audio material without visual aids that support it. It follows that the development of auditory skills should be taught more carefully, since it is in this block that the degree of psychological constraint in front of a foreign speech is most strongly manifested, especially when it comes to contextual Russian.

Its peculiarities are imposed by the fact that often in educational institutions the emphasis is on the development of auditory skills based on educational listening. There is the difference defined between communicative and educational listening. In the process of 
educational listening, the formation of speech hearing and the skills of recognizing lexical and grammatical material, the skills of understanding and evaluating the listened. Communicative listening is a complex speech ability to understand speech by ear when it is reproduced once. The emphasis on academic listening to some extent contradicts the very purpose of teaching listening, since in life the student will have to deal more with communicative listening, that is, the ability not only to perceive information by ear and analyze it from the point of view of the proposed conventions, but also to analyze information for further communication in the context of a speech situation.

Understanding a foreign language by ear in a speech situation of communication is not only a perceptual process, but also a social activity.Therefore, along with the auditory skills and abilities, it is necessary to develop the resulting ability to conduct a conversation, since during the conversation, both interlocutors act in the roles of "listener" and "speaker".

In this regard, T. Rost identifies several types of auditory skills, which, in his opinion, should be developed in students in the process of teaching listening for its further successful implementation in everyday activities. These include: "auditory skills aimed at the monologue of the communicator (these are the most perceptual auditory skills, since in such cases the listener is often deprived of the opportunity to communicate with the speaker); auditory skills, which are a component of an active communicative process, when the listener is also the speaker (the development of these skills is a priority in the formation of auditory skills, since participation in communication from the point of view of listening is a multi-stage process that includes perception, classification, analysis and reproduction of the response information); auditory skills aimed at critical analysis of the information being listened to (from the point of view of the researcher, this type of auditory skills is basic, since the formation of one's own assessment of the material heard is the highest degree of information perception by ear and a necessary skill in almost all cases of auditory perception of information); auditory skills of a "leisure" nature (these skills imply a "native" perception of information by ear, that is, the absence of the need to make unnecessary efforts. "Leisure" auditory skills are necessary, first of all, to overcome the psychological barrier. In situations where the involvement and interest of the individual prevails over the need to focus on the exact reproduction of the means of another language (usually these are cases of rest and leisure activity), it is very important to achieve the perception of information by ear with almost no effort, so that further communication in a foreign language proceeds without psycholinguistic difficulties and does not interfere with "entertaining" human activities).

Based on this classification of auditory skills, it can be concluded that listening is one of the most personality-oriented types of speech activity. It means that in its development, one should rely not only on the development of mechanical auditory skills, but also on the interests of students. It is especially important to take this into account when teaching RFL, since the original and vibrant Russian culture, as well as the "ambiguous" Russian mentality, captivate students along with language learning. At the same time, it is not enough to represent only the monumental part of the country's historical and cultural life. Young people want to know more and more about how things are going now, what worries and interests their peers in Russia. That is why, in our opinion, podcasts are the most relevant means for developing auditory skills among learners of Russian as a foreign language.

Podcasts as a phenomenon of modern pop culture are used mainly for entertainment purposes.However, due to well selection, they can be a fun and effective educational tool. Of course, the lack of educational podcasts for the discipline of RFL is a negative factor, since not all podcasts of an entertaining nature are suitable for use in the classroom, so the teacher has to spend much more time selecting the necessary material, which is still imperfect.Analysis of several popular podcasting platforms ("Meduza", "Arzamas", 
"Yandex Music", - "PodFM.RU”, "Radio-T", "Russianpodcasting", "VK Podcasts") allowed us to highlight the main advantages of podcasts for the development of auditory skills studying RCT.Among them: a variety of topics and directions;live oral speech, in which you can hear the Russian language that people now use in society;communicative component; understanding of precedents.

So, it is possible to match a podcast for any educational topic and the purpose of the lesson, which will not only allow you to fulfill the tasks set by the teacher, but also learn natively about the culture and modern events in Russia. This helps not only to perceive the actual linguistic paradigm, but also to see the real "work" of the language, linguistic phenomena and connections in practice. Moreover, a podcast is more than often a conversation between two or even more people, then the student automatically perceives not only the transmitted information, but also the norms of ethics adopted during communication. Often in daily speech, which is prevalent in the field of podcasting, people use precedent units that, given the high level of contextuality of the Russian language, are almost inaccessible for a foreigner to understand. Observing the use of precedents in a conversation between two people can help a student to understand their lexical and grammatical role for independent use, and therefore express their own partial belonging to the studied culture.

\section{Conclusions}

Summarizing the above knowledge, we can conclude that a future separated discipline of precedent texts should be based on methodological tools that allow developing both the auditory skills of students and, at the same time, involve students of Russian as a foreign language in understanding the uses of everyday speech.In this regard, the most appropriate methodological tool can be podcasts and, more precisely, educational podcasts created by native speakers of the Russian language for non-native ones.

The use of a podcast as an audio material when foreign students study Russian has a number of positive aspects:

- the speaker's speech in the podcast is usually well structured, diction and lexical forms are verified.This makes it easier to understand and learn certain "academic" speaking patterns; - with the help of a podcast, you can simultaneously delve into the details of the specialty being studied, learn about the development of science in the chosen field and study Russian;

- podcasts are examples of "live" Russian. Taking into account the fact that for Russia this is a fairly new information phenomenon, it is created by "young for young", which means that a foreign student will hear the same speech in the podcast that he can hear in daily life.This contributes to the formation of the necessary speech competencies and speech etiquette.

Podcasts "allow you to solve a number of methodological problems: the formation of auditory skills and the ability to understand a foreign language by ear, the formation and improvement of auditory-pronunciation skills, the expansion and enrichment of the vocabulary, the formation and improvement of grammatical skills, the development of speaking and writing skills" [3].

In the course of the planned discipline "Precedent Texts", podcasts will be not only a teaching tool as close as possible to speech reality, but also a mean into which precedent units can be introduced as naturally as possible, while showing various cases of their use and participation in communication.

Summing up, we can say the following.

Precedent texts in the methodology of teaching RFL are not a relatively new phenomenon, since attempts to include them in the process of learning Russian by foreign students appeared along with the emergence of the RFL methodology. 
There is no general system of teaching to understand precedent texts, and teachers use some of the available research in accordance with their experience and educational goals necessary for a specific group of students;

The difficulties associated with understanding precedent texts later become communication barriers for learners of Russian as a foreign language;

Understanding precedent units is associated not only with understanding and using speech in a "practical" sense, but also with auditory perception, the development of the auditory skills of foreign students;

It is necessary to single out precedent texts as a separate discipline in the didactic paradigm of RFL, in order to expand the time for studying this aspect of the Russian language and, as a result, improve the quality of understanding not only of these units, but also of language and culture in general in the context of sustainable language education.It is worth mentioning that the allocation of this discipline will have a positive effect not only on students of Russian language studies, but also for native speakers of the Russian language for a deeper understanding of their own language picture, culture and history of the country;

In the selected discipline, it is possible to focus on the development of students' communication skills by stimulating auditory skills, while showing the fullness and semantic content of the use of precedent texts in speech. This can be achieved with the help of podcasts, which act as a toolkit for listening, but containing the basis for representing the current state of the Russian language and its precedence and contextuality;

For the above purposes, the development of educational podcasts created by native speakers of Russian for foreign citizens is best suited. Educational podcasts acting as a methodological development can preserve the naturalness and precedent nature of Russianspeaking speech, which is necessary in its everyday use, and at the same time include the necessary information on the topic under study in the system of linguistic sustainable education.

\section{Reference}

1. G. Tessuto, English for Specific Purposes, 37 (1), 13 (2015)

2. M. Fominykh, B. Uskova, N. Vetlugina, T. Luzjanina, L. Volkova, Elementary Education Online, 19, 1005 (2020)

3. O. Bilash, Culture in the language classroom (2011), http: //www.educ.ualberta.ca/

4. Unesco Declaration on cultural diversity,2002), http://unesdoc.unesco.org/

5. A.A Evtyugina, Precedent texts in the poetry of V. Vysotsky: (to the problem of idiostyle): abstract of dis.... candidate of philological sciences: 10.02.01, 17 (1995)

6. A. A. Evtyugina, L. E. Volkova, Nov.inf.those.in arr. and Science, 3, 47 (2020)

7. V.V.Krasnykh, Ethnopsycholinguistics and linguoculturology: A course of lectures, 284 (2002)

8. V.G.Kostomarov, N. D.Burvikova, Russian language abroad, 1, 73 (1994)

9. EI Passov Fundamentals of communicative methods of teaching foreign language communication, Communication as the goal of learning, 276 (1989)

10. E. Yu. Popova, Precedent phenomena in modern artistic discourse (on the material of $V$. Pelevin's novels "Generation $P "$ and "Numbers": dissertation ... candidate of philological sciences, Theory of language. Saratov, 22 (2012)

11. N. D.Galskova, Modern methods of teaching foreign languages. Guidelines for the teacher, 165 (2000)

12. Yu.N.Karaulov, Russian language and language personality, 216 (1987) 